\title{
Leveraging Strengths and Meeting Demands: The Construction of a Modern and Comprehensive Electronic Reserves Service at Central Michigan University
}

\author{
TIMOTHY PETERS ${ }^{1}$ \\ Central Michigan University, Mount Pleasant, Michigan, USA \\ KENNETH J. SANNEY ${ }^{2}$ \\ Central Michigan University, Mount Pleasant, Michigan, USA
}

\begin{abstract}
The digitization of information has transformed how colleges and universities function; virtual classrooms, online course management systems, and digitized content have become the norm. Electronic reserves are the fulcrum of this transformation. Colleges and universities now have the opportunity to utilize their resources in new and transformative ways in order to provide the most effective education experience possible. For these dynamic opportunities to be fully realized, however, institutions must address the unique challenges that digital media create. This article analyzes how Central Michigan University changed the way it operates to create a modern and comprehensive electronic reserves system.
\end{abstract}

Keywords. Electronic reserves, academic libraries, copyright law, off-campus programs, online classes, licensing, copyright clearance

\section{Introduction}

An Army Colonel stationed in Stuttgart, Germany sits down to his computer and begins watching a video on supply-chain management; halfway around the world, a nineteen-year-old in Mount Pleasant, Michigan reads an online article on racial justice; and in Atlanta, Georgia a thirty-year-old mother of two is enjoying a cappuccino in a coffeehouse while watching a recorded lecture that contains a slide presentation on financial analysis, planning, and control.

\footnotetext{
${ }^{1}$ Timothy Peters is Director of Information Services and Chair of the Copyright Committee, Central Michigan University Libraries, Park Library 225, Mount Pleasant, Michigan 48859 (E-mail: peter1t@cmich.edu).

${ }^{2}$ Kenneth J. Sanney is Assistant Professor of Business Law \& Regulation and Copyright Committee Member, Department of Finance \& Law, College of Business Administration, Central Michigan University, 340 Sloan Hall, Mount Pleasant Michigan 48859 (E-mail: ken.sanney@ cmich.edu).
} 
What do these three people have in common? They are students at Central Michigan University (CMU).

Technology has rapidly expanded the opportunities for institutions of higher learning to reach a dynamic and much more diverse set of students than ever before. Yet, to take advantage of these opportunities, academic institutions have had to change the way they operate. Nowhere has this need for change been more apparent than in college and university libraries and their handling of reserve materials. The time of professors requesting that their college or university library place books, journal issues, and other physical items on a Reserve shelf to be checked out, photocopied, and returned has given way to an era of electronic reserves where class-related content is, in so many cases, digitized and placed into either a stand-alone electronic reserves system or directly into an institution's course management system (CMS). Furthermore, the breadth of the content that is provided in this environment is remarkable in its scope, which ranges from traditional scholarly articles to new media such as interactive video exams.

The proliferation of online classes in the nation's colleges and universities and the corresponding increase in the use of online CMS's have caused significant changes in how academic libraries offer course-related reserve materials. Within this new digital environment, academic institutions are increasingly confronted with both strategic and tactical challenges such as copyright restrictions, economic constraints, and usage barriers that simply were not substantial issues under the much simpler pre-digital print reserves model.

The transition to a modern model of electronic reserves--a model that not only satisfies the needs and demands of the ever-growing number of electronic reserves users, but also ensures that the institution will be compliant with copyright law and academic best practices while operating within reasonable budgetary parameters--requires an academic library to acknowledge, 
address, and continually reevaluate their approach to these technology-driven challenges. This article examines and details CMU's approach in addressing these challenges and implementing a comprehensive electronic reserves service with an emphasis placed upon quantitative testing of the outcomes of the service.

Before CMU's approach to these technology-driven challenges is examined, this article first reviews the current state of the scholarly literature analyzing the systems and challenges of managing electronic reserves in the current academic environment. This literature review will provide the reader with a context in which to view CMU's approach at addressing these obstacles within its electronic reserves system.

Following the literature review, a historical descriptive analysis of the evolution of CMU's electronic reserves system will be explored. This historical descriptive analysis pays particular attention to the extrinsic pressures driving the evolution of this system on CMU's campus. Issues such as CMU's history of off-campus instruction and the rise of online courses will be examined as catalysts of disruptive change.

Once the contextual and descriptive foundations have been laid, CMU's approach to developing a modern model of electronic reserves will be examined in detail. This examination will pay particular attention to the processes and procedures CMU's staff and administration took to overcome the legal, economic, and usage challenges detailed in the previous sections.

Lastly, this article advances the literature by providing quantitative data analysis of the outcomes of CMU's approach to developing a modern model of electronic reserves. This quantitative analysis draws upon data from university-wide surveys of users and also from budgetary and other financial data collected by the university. The combination of this quantitative analysis with the preceding qualitative descriptive analysis provides a complete and 
detailed picture of how CMU changed the way it operates to successfully implement a modern and comprehensive electronic reserves service.

\section{Literature Review}

With the ever-increasing student and faculty demands for access to electronic materials ranging from journal articles to live and on-demand video, it is little wonder that scholarship related to electronic reserves has played an increasingly prominent role in the professional and academic literature. The state of the current literature expands our understanding of a number of issues regarding electronic reserves ranging from the inherent difficulties of navigating copyright law (Gould, Lipinski, \& Buchanan, 2005; Gerhardt \& Wessel, 2010; Gasaway, 2010) to broad studies examining the evolution of electronic reserves at the libraries of our nation's institutions of higher education (Oliver, 2008; Goodson \& Frederiksen, 2011) to the specific approaches individual libraries have taken to address the economic and legal constraints new technology has visited upon them (Quartey, 2007; Cubbage, 2007; Woodman, 2007; McCaslin, 2008; Wagner, 2008; Bridgewater, 2008).

Attempts to address copyright difficulties cut a broad swath through this body of literature. The examination of indeterminable issues such as the application of the fair use doctrine, licensing of external digital content, the digitization of analogue works, and hosting and management of both externally generated and user-generated content play an important role in this area of research. As Laura Gasaway's recent article (2010) points out "prior experiences with analog materials cannot answer all of these questions because digital works present some new, unique, and challenging copyright issues" (p. 777). 
The difficulty copyright law has created for libraries can best be demonstrated by contrasting Gasaway's conclusion from her Summer 2010 article that "[t]here are also some materials that clearly are "safe" to use, which include: (1) public domain material, (2) works licensed by the institution, (3) material that is licensed under some of the Creative Commons licenses that permit reuse, and (4) works for which the student has obtained permission" (p. 777, emphasis added) with the 2012 United States Supreme Court decision in the case of Golan $v$. Holder that affirmed the federal government's authority to extend copyright protection to works that had previously been in the public domain. Not only do librarians have to worry about the indeterminable nature of the case-by-case application of the fair use doctrine, but the public domain is now a malleable idea that Congress may redefine as it sees fit.

In spite of the Golan v. Holder decision, Gasaway's article provides well-articulated and sound analysis and advice regarding the management of electronic reserves within the bounds of copyright's ever changing landscape. Her article is especially helpful in its treatment of usergenerated content in an electronic reserve system.

Gould, Lipinski, and Buchanan (2005) took a much more narrowly-tailored approach when they undertook a study of 67 American Research Library Association institutions' fair use policies as they specifically related to both traditional analogue reserves and emerging electronic reserves. Among their conclusions is the finding that the majority of the policies that were reviewed were static and did not properly reflect the complexities and nuances of the fair use doctrine. They further concluded that such policies were, in most cases, "too severe and restrictive," (p. 196) due to most institutions addressing this challenge by implemented arbitrary limits on copying of published works (e.g., policies limiting copying of any published work to $10 \%$ of the total work). Lastly, the authors warn against the pitfalls that a formulaic use of such 
polices can pose and recommend each institution formulate their policy to take into account continuing legal developments regarding fair use, the institution's tolerance for risk, and any other unique institutional circumstances.

The overabundance of caution and the oversimplified and formulaic application of copying limits found in these authors' study further demonstrates the difficulty encountered by libraries when trying to reconcile legal and economic constraints, disruptive technology, and user demand.

Most recently, Goodson and Frederiksen (2011) conducted a broader "environmental scan of selected academic libraries across the United States" in an effort to "understand the present landscape of electronic reserve services in academic libraries" and "get a general sense of any changes taking place in this area of library operation" (p.35). According to the seminal work of Fahey and Narayanan (1986), environmental scans are a methodology used to identify changing trends and patterns in the hopes of forecasting the future direction of these changes and patterns and thereby assess their organizational impact.

Goodson and Frederiksen's environmental scan was conducted across a number of primarily academic institutions with the intent to "provide a snapshot ... of the e-reserve environment in early 2010" (p. 35). The authors find that academic libraries fall primarily into one of three general categories: (1) a full service e-reserve model where the "library remains at the center of the reserves process providing full service from the beginning to end"; (2) a selfservice e-reserve model where "individual faculty or other academic support units outside the library are responsible for placing supplementary reading material into individual course spaces ..."; and (3) a hybrid service model that has a limited range of services that fall somewhere short of the full-service model but offer e-reserve services that are greater than the self-serve model (p. 
35). In this last category, there are a diverse set of e-reserve services offered across a broad continuum that ranges from "library focused" e-reserve services to "non-library focused" (p. 54) e-reserve services that rely on CMS's.

The most drastic trend Goodson and Frederiksen's environmental scan identified was the growth of the number of academic institutions moving from the first or third categories (i.e., a full service or hybrid models) to the second category (i.e., self-service models). The authors postulate that "budget constraints and declining financial support for library operations and concern about copyright compliance, along with staffing and workload issues, have forced libraries to re-evaluate many internal processes" (p. 54). These are the type of challenges identified in the introduction to this article and discussed more fully below.

Goodson and Frederiksen speculate, however, that it may not be these challenges that serve as the most significant driver of change. According to the authors, "[p]erhaps the most significant driver of change ... has been the rapid adoption by academic institutions across the country of course management systems ... that allow for and support a self-service model for creating supplementary course material" (p. 54). While the underlying supposition to this statement is difficult to argue against (the impact CMS's have had on electronic reserves is undeniable), the speculative and unsubstantiated nature of the statement seems to unnecessarily undermine their data set, analysis, and conclusions.

The conclusion drawn from the data--that "budget constraints and declining financial support for library operations and concern about copyright compliance, along with staffing and workload issues, have forced libraries to re-evaluate many internal processes" (p. 54)--is more consistent with the literature from other authors than is their speculative focus on CMS's as the most significant driver of change. These latter authors have focused on specific institutional 
approaches to solve such broad ranging issues as developing a university copyright policy (Quartey, 2007), efficiently educating faculty on electronic reserves (Quartey, 2007; Woodman, 2007; Wagner, 2008), efficient solutions to transaction costs of staff demands in copyrighted management and licensing (McCaslin, 2007; Cubbage, 2007), course management systems (Cubbage, 2007), interacting with the publishing community (Cubbage, 2007), administrative burdens and licensing costs (Bridgewater, 2008).

While CMS's are one driver of change providing a challenge to the transformation of reserve systems, they are but one of many catalysts and challenges that must be addressed when developing a modern model of electronic reserves. To focus on one catalyst or challenge at the exclusion of the others would create intolerable risk for most institutions.

With this context now developed, it is time to shift our examination to CMU's reserve system, its users, and the policies it undertook to transform its e-reserve system into a comprehensive and modern full-service electronic reserve system.

\section{The Case of Central Michigan University}

Central Michigan University is located in Mount Pleasant, Michigan and is a public, fouryear institution that grants Bachelor, Master, and Doctoral degrees. During the Fall 2011 semester, the total university enrollment was 28,311 (Central Michigan University, Office of Institutional Research, 2011).

A significant part of CMU's enrollment, however, has long been students who take classes away from the main campus through the university's Off-Campus Programs division, and in the Fall 2011 semester these students accounted for 7,091 of the university's total student body. (Central Michigan University, Office of Institutional Research, 2011). What is today 
known as Off-Campus Programs was founded in 1971 as the Institute for Personal and Career Development (IPCD), which was charged with offering non-traditional learners and working adults located away from the main campus opportunities for educational and career advancement. The university "recognized a need to reach out to what we then called the educationally disenfranchised adult - the adult who, because of career and/or family responsibilities, couldn't participate in higher education as it was traditionally offered" (Central Michigan University, 1992, p. 2).

In 1976, CMU's Off-Campus Library Services (OCLS) was formed to provide library services to those students and faculty participating in the degree programs offered off campus. The responsibility of the OCLS was two-fold: (1) to provide reference and research assistance to distance students and faculty and (2) to deliver copies of articles and book excerpts, books, videos, and other library materials needed by faculty and students for their class instruction and research. Reference assistance and instructional services continue to be handled today by the OCLS librarians, while the delivery of materials to distance learners was, until very recently, handled by the Document Delivery Office (DDO), which was a unit within the OCLS.

Since the students enrolled in distance programs were not able to easily access items from the library's Reserve shelves located in Mount Pleasant, Michigan, a system of copyright clearance was created to provide faculty with a satisfactory way of making course readings and required materials available to their students. Under this model, instructors identified the readings they wished to use for a particular class and the DDO obtained full-text copies of the items, one semester worth of usage permissions, paid any associated copyright fees, and distributed the materials to the faculty member. During the 1980's and 1990's document delivery took the form of mailings of photocopied materials, and, later, the mailings of a compact disks 
that contained copies of the reserve items. The use of electronic reserves began to increase with the University's migration to Blackboard as its course management system during the 2002-03 academic year. By the 2006-07 academic year, the DDO was routinely placing materials directly into Blackboard for the purpose of e-reserves (L. Bellinger, personal communication, December $8,2011)$. The extent of CMU's migration to electronic reserves is shown by recent statistics: in January of 2012 , more than $96 \%$ of all reserve material usage came in the form of hits to ereserve materials posted in Blackboard as opposed to traditional print reserve material check outs (D. Thomas, personal communication, February 8, 2012).

Under this model, all the work associated with locating and posting electronic reserves materials was handled by the OCLS and, if there were fees associated with using a particular item for class purposes, these fees were paid up front by the OCLS. This process allowed items to be used immediately for class purposes, and in many cases items were mounted into Blackboard before the class even began. The enrolled students were then billed for all copyright usage fees related to their particular class. If, for example, an instructor had a class of 15 students and placed four items on reserve at a total cost of $\$ 90.00$, each student would be assessed a copyright fee of $\$ 6.00$ for that class. Under this arrangement, the responsibility for the usage costs related to electronic reserve items fell squarely on the shoulders of the students enrolled in the class.

This copyright clearance arrangement was, however, limited to off-campus classes. Since on-campus instructors and classes had long had access to the physical Reserve shelves in the Park library, no effort had been made to create any kind of copyright clearance service for them. Materials (typically from the library's collections) were placed on reserve within the library and students came to use them. Eventually on-campus instructors began to adopt Blackboard and 
place materials on electronic reserve within their course shells, but the lack of a defined copyright clearance service for on-campus classes limited what they could do. In keeping with the doctrine of academic fair use (Copyright Act of 1976, 17 U.S.C. § 107 (2011); U.S. Copyright Office, 2009), instructors were able to use an item one time without having to seek permission or pay licensing fees, but then had to find a completely new item for each subsequent semester. Obviously, this "one-and-done" arrangement was not ideal for the on-campus faculty, many of whom had located very appropriate materials and wished to use them more than once.

The imbalance created by having these two separate electronic reserve procedures became problematic as CMU began to create and offer more online classes. With the recognition of the importance of the online teaching model to the future of higher education, CMU made a deliberate and concerted effort beginning in the 2007-08 academic year to increase the number of online course offerings to its students. The University, with its long history as a national leader in distance learning, was ideally positioned to pursue such an endeavor. From the 2006-07 academic year to the 2010-11 academic year CMU increased the number of unique courses offered from 68 to 213 (M. Roestel, personal communication, May 10, 2011). This push continues today, with CMU not only creating more online courses, but offering a number of degree programs entirely online.

A big part of this new online initiative was the creation in 2007 of a unit called CMU Online to oversee the development and delivery of online classes. This new unit grew out of what had been a smaller unit within Off-Campus Programs; the new emphasis on online classes meant that the smaller unit became "promoted" to a much larger role within the university.

It is important to note that, while CMU Online is regarded as its own division within the university (CMU officially recognizes itself as having three campuses: on campus, off campus, 
and CMU Online), the administrative responsibility for it remains for all practical purposes with Off-Campus Programs. What this also means is that the library services and the copyright clearance service long extended to off-campus classes through OCLS are also extended to CMU Online classes.

As online classes became more integrated into the curriculum the responsibility for teaching the classes began to shift from adjunct instructors hired through Off-Campus Programs and CMU Online to regular on-campus faculty members, a fact that was accelerated by CMU's shared governance structure that in 2009 placed the responsibility for the development of new online courses within the individual academic departments. An anticipated result of on-campus faculty developing online courses was that these very same faculty members would also be heavily involved in teaching these online classes. With this increase of on-campus faculty's involvement in online teaching, the CMU Libraries began to hear this question more frequently: "Why don't I have access to a full copyright clearance service for my on-campus class like I have for my online class?" It quickly became apparent that having two separate copyright clearance systems at a university that was becoming increasingly blended was problematic and likely unsustainable.

\section{Moving Toward a Single System}

The beginning of the end for the University's dual system of copyright clearance came in February of 2009, when the CMU Copyright Committee proposed that the copyright clearance services used by Off-Campus Programs and CMU Online be extended to on-campus classes as well, thereby uniting the University under a single and consistent copyright clearance model and offering a new level of service to on-campus classes. This model, consistent with the history at 
CMU, was to remain a full service e-reserve model where the "library remains at the center of the reserves process providing full service from the beginning to the end" (p. 35), consistent with the first of Goodson and Frederiksen's (2011) three general categories of academic libraries ereserve environment.

To this end, the committee worked with the CMU Libraries and supported their application for a CMU 2010 Grant to investigate the possibility of extending this service to all classes. The CMU 2010 Grants were institutional grants designed to allow departments across the university to explore new initiatives and projects that would benefit the institution and move CMU forward. In March 2009, the Libraries were informed that they had been awarded a oneyear CMU 2010 Grant, effective July 1, 2009 through June 30, 2010. The administration of the grant was the responsibility of Timothy Peters, then Director of Off-Campus Library Services and Chairperson of the CMU Copyright Committee.

Once the grant was obtained, the process of gaining support from various constituencies around the campus took priority. With the help of the Dean of Libraries, conversations with various campus constituencies, including the Academic Senate and representatives from the University's accounts payable office, were undertaken. The most important conversation, however, was with the university's Council of Deans (COD), whose approval was needed before the project could be moved forward. In late March of 2009, the CMU Copyright Committee drafted a statement proposing five funding models to be considered for the new university-wide copyright clearance service. The statement was passed on to the Dean of Libraries for consideration. The five proposed funding models were:

1. Bill all copyright costs to the students in the classes using the material (which was the model then in place for off-campus and online classes). Pros: The actual users of the material would bear 
the costs and the University would avoid additional institutional expense; Cons: It would mean additional costs for students and new university-wide billing procedures would have to be put in place.

2. Bill the colleges actually offering the courses for the costs. Pros: The colleges would bear costs proportionate to their involvement in online instruction; Cons: The departments may not have the ability or the willingness to pay.

3. Assign a flat copyright fee to all enrolled students at CMU. Pros: It would streamline the process by eliminating the need to bill individuals; Cons: It would mean additional costs for students and students in classes that do not use electronic reserves may consider the fee unfair.

4. Have the University provide the library with a 'copyright fund' each year and have the library pay all associated costs from it. Pros: Streamlines the process by eliminating billing paperwork and centralizes all aspects of the service; Cons: There was a question as to where the funding would come from and concerns about the fact that, since this expanded University-wide service would be something completely new, it would be impossible to gauge the financial impact of a comprehensive copyright clearance service until the service was implemented and the fees were paid.

5. Obtain an annual license through the Copyright Clearance Service (CCC) in combination with either Option \#1 or \#2. Pros: Streamlines the process with a single, up-front payment for most transactions; Cons: The agreement would not apply to materials not obtained through $\mathrm{CCC}$ and would still require the creation of new billing procedures.

After discussion between the Dean of Libraries and the Copyright Committee, it was decided that Options \#1 and \#2 would be taken forward to the Council of Deans for consideration. The Dean and the Copyright Committee realized the importance of establishing a comprehensive service and felt that these two options offered the greatest likelihood for success. On May 13, 2009, representatives from the CMU Libraries and the Copyright Committee met with the COD to discuss the proposed copyright clearance service and the two service options in 
greater detail. While the COD was immediately supportive of the idea of the new comprehensive service, there was serious deliberation and discussion concerning the funding of the initiative.

After further discussions at the Council of Deans and University Provost levels, it was decided that the university would fund and the library would administer a trial comprehensive copyright clearance service for a period of one year (this being very similar to Option \#4 listed above). The trial would begin upon the completion of the CMU 2010 Grant on June 30, 2010. At some point during the Spring 2011 semester, the trial would be evaluated to determine whether the project was meeting its aims and operating within reasonable financial parameters. If the results of the evaluation were positive, there was a likelihood that the service would be continued; if the service was not meeting its aims or was incurring unexpected and unreasonable expenses, it would likely be discontinued and other options would be explored. The degree to which the University Administration believed in the necessity of offering a comprehensive copyright clearance service is indicated by the fact that they approved the project despite not being provided with confident estimates of future costs. As an entirely new service to a clientele who had never had access to such services -- but who may well decide to use the services very heavily -- it was impossible to confidently estimate the potential costs.

At the same time, the CMU Libraries were reorganizing staff in preparation for this new service. In order to provide a more unified service to faculty and to streamline processes within the library it had been decided to combine the copyright clearance services within OCLS with the main library's Course Reserves office, thereby creating the a new department called Course Reserves and Copyright Services. This new office would have the responsibility of providing traditional print and electronic reserves service to all CMU classes at all three official campuses (on-campus, off-campus, and online). In July 2009, shortly after the CMU 2010 Grant began, 
this new office was officially created and implemented. A new online interface for the Course Reserves and Copyright Services office was developed within the library's website and the online submission of reserve materials requests began.

Also in July 2009, a survey of on-campus faculty was conducted to determine their usage of electronic reserve materials. The survey was distributed to the approximately 700 full-time oncampus faculty members at CMU. The survey was necessary because the library realized that, since the on-campus faculty had never had access to a formal copyright clearance service, there was not any data beyond the anecdotal as to how frequently on-campus faculty use copyrighted materials in their instruction. It was also hoped that the findings from the survey would help in assessing the costs the university might incur once the copyright clearance service was expanded across the entire university. As pointed out in the Cons section of Option \#4 above, since this was a completely new service to on-campus faculty it was very difficult to foretell what expenses would be incurred. Key findings from the July 2009 faculty copyright survey included:

- $\quad 76.4 \%$ of 150 respondents said they use copyrighted materials in their instruction;

- $\quad 63.5 \%$ of respondents claimed they use copyrighted materials in "All of my classes" or "Most of my classes";

- $\quad 34.5 \%$ of respondents claimed that they use 1 to 3 items per class, $22.3 \%$ claimed they use 4 to 7 items per class, and $23.0 \%$ claimed they use 8 or more items per class.

The survey demonstrated that considerable portions of the on-campus faculty were substantial users of copyrighted materials in their teaching and, therefore, the library could reasonably expect these same faculty members to regularly make use of the new copyright 
clearance service. While the survey results caused some concern from a financial standpoint, they also led the library to conclude that the on-campus faculty would be appreciative of a comprehensive electronic reserves service.

As the 2009-10 year began, the Course Reserves and Copyright Services office received some very good news from the CMU Office of General Counsel. The office, after having reviewed licensing agreements between vendors and the CMU Libraries and having looked at the then current copyright landscape, made the determination that materials from the CMU Libraries' collections, including book excerpts and journal articles, could be placed on electronic reserve without having to gain further permission from the copyright holder or pay further usage fees. This determination covered usage beyond the electronic reserves usage permitted by the library's vendor contracts. In the short term, this determination helped to ease some worries related to the overall costs of the new service; in the long term, it would prove to have a tremendous impact on the overall viability and success of the service.

During the Fall of 2009, planning was undertaken for a pilot program to be held during the Spring 2010 semester. The pilot program would be a small-scale exercise in preparation for the proposed comprehensive copyright clearance service that would be available across the University after July 1, 2010. A total of 13 on-campus faculty volunteered to participate in the Spring semester pilot, placing 220 items on electronic reserve for a total of 21 class sections. This was accomplished at a total cost of $\$ 1,133.04$, which was paid for from the budget of the CMU 2010 Grant. This pilot was valuable because it allowed on-campus faculty to have access to a true copyright clearance service and because it allowed Course Reserves and Copyright Services to implement, test, and revise the processes and procedures it would use once the service became available to all CMU classes. 
On June 30, 2010, the CMU 2010 Grant ended and the CMU Libraries debuted its new comprehensive copyright clearance service.

\section{Findings from the 2010-11 Year}

Once the CMU 2010 Grant ended, the one-year trial period for the University's new comprehensive copyright clearance service began. Administered by the library's Course Reserves and Copyright Services office, the new service has been a success in terms of both how it has been received and used by the CMU faculty and how smoothly it has run, from the library's point of view. Additionally, early fears about potentially high costs for the service have been eased by the data that has been collected. Here are select findings from the first year of the service:

- $\quad$ During the 2010-11 year, a total of 2,904 items were placed on electronic reserve by on-campus, off-campus, and online instructors.

- Approximately $71 \%$ of the items requested to be placed on ereserve were found within the library's collections. Given the 2009 determination by the CMU Office of General Counsel, this figure is of tremendous significance. It meant that the University did not incur costs for almost three-quarters of the materials it placed on electronic reserve.

- $\quad$ For the entire 2010-11 year, the CMU Libraries paid only $\$ 8,439.43$ to place materials on electronic reserve for its oncampus, off-campus, and online classes. Again, the CMU Office of 
General Counsel's decision on materials from the library's collections was a significant factor in this figure being so reasonable, though it's worth pointing out that an additional 346 items were used under the academic fair use doctrine, which allows an item to be used one time, for teaching purposes, without having to license the work. Any subsequent uses of these items will, of course, require proper licensing (i.e., permissions and payment).

- In the end, only 445 of the 2,904 items required payment of licensing fees.

- It was found that $38.9 \%$ of the items placed on electronic reserve during the Fall 2010 semester were used again during the Spring 2011 semester. This is a significant figure since the on-campus faculty never had the opportunity to re-use reserve materials before the 2010-11 year, though the library feels the figure may actually be higher once the Fall 2011 numbers are tabulated because many CMU classes are offered only once per year (many Fall 2010 classes did not run again until Fall 2011).

In April 2011, the CMU Libraries administered a survey to 117 faculty members who had used the new copyright clearance service during the 2010-11 academic year. A total of 41 faculty responded and the feedback was overwhelmingly positive. Overall, $97.6 \%$ of respondents were satisfied with the copyright clearance service offered by the CMU Libraries and the same percentage replied that they plan to use the service again in the future. Among the many very 
positive open-ended comments were "It is SO much more convenient than at any other school I have taught at. I can pretty much email my syllabus to the library and expect [the readings] to be posted within a couple weeks" and "This is a wonderful system - the librarians were very helpful in the process. I could assign classic journal articles as well as "cutting edge" readings that are not yet represented in readers, and I was able to keep students' book costs down as a result." It is worth pointing out that $80 \%$ of the respondents were on-campus faculty who never had access to such a service before.

From the data gathered and the survey feedback, it is obvious that the library is providing a valuable service to CMU faculty and students, and at a cost that is well within the bounds of the University's budget. The comprehensive copyright clearance service continues to be offered past the one-year trial period, which indicates that the university finds the service not only essential to the success of its educational mission, but also agreeable from a financial standpoint.

\section{Conclusion}

Having recognized the need for increased access to materials used in the classroom, Central Michigan University was able to create a comprehensive copyright clearance service that meets the instructional needs of faculty as well as the information needs of students, and do it within the limits of current copyright law, budgetary concerns, and best practices. Now in its second year of existence, the service is fully integrated into the workflow of the library, much appreciated by its users, and operating within the hoped-for financial parameters. The library will monitor this service going forward, to ensure that it continues to contribute to the University being able to meet its instructional and educational goals. 


\section{References}

Bridgwater, R. (2008). Shifting responsibility for electronic reserves copyright permission from the academic departments to the library: From confusion to cooperation. Journal of Interlibrary Loan, Document Delivery \& Electronic Reserve, 18(2), 141-152.

Central Michigan University, Office of Institutional Research. (2011). History of headcount, FTE, FYES enrollment by campus. Retrieved from http://www.cmich.edu/documents/OIR/enrollment/headcount_fte_fyes_2011.pdf

Central Michigan University. (1992, Fall). CMU celebrates 20 years of off-campus degree programs. The Communicator: 20th Anniversary Issue, 2-6.

Copyright Act of 1976, 17 U.S.C. $\S 101$ et seq. (2011).

Cubbage, C. (2007). The changing cost environment of managing copyright for electronic reserves. Journal of Interlibrary Loan, Document Delivery \& Electronic Reserve, 18(1), 57-66.

Fahey, L., \& Narayanan, V. (1986). Macroenvironmental analysis for strategic management (The West Series in Strategic Management). St. Paul, Minnesota: West Publishing Company.

Gasaway, L. (2010). Libraries, digital content, and copyright. Vanderbilt Journal of Entertainment \& Technology Law, 12(4), 755-778.

Gerhardt, D. \& Wessel, M. (2010). Fair use and fairness on campus. North Carolina Journal of Law \& Technology, 11(3), 461-530.

Golan v. Holder, 565 U.S. , 132 S.Ct. 873 (2012).

Goodson, K. \& Frederiksen, L. (2011). E-reserves in transition: Exploring new possibilities in e-reserves service delivery. Journal of Interlibrary Loan, Document delivery \& Electronic Reserve, 21(1), 33-56.

Gould, T., Lipinski, T. \& Buchanan, E. (2005). Copyright policies and the deciphering of fair use in the creation of reserves at university libraries. The Journal of Academic Librarianship, 31(3), 182-197.

McCaslin, D. (2008). Processing electronic reserves in a large academic library system. Journal of Interlibrary Loan, Document Delivery \& Electronic Reserve, 18(3), 335-346. 
Oliver, A. (2008). Current practices and philosophy on electronic reserves, course management systems, and copyright compliance: A survey of the council of public liberal arts libraries. Journal of Interlibrary Loan, Document Delivery \& Electronic Reserve, 18(4), 425-437.

Quartey, S. (2007). Developing a campus copyright education program: Conquering the challenge. Journal of Interlibrary Loan, Document Delivery \& Electronic Reserve, 18(1), 93-100.

United States Copyright Office. (2009). Reproduction of copyrighted works by educators and librarians. (Circular 21). Retrieved from http://www.copyright.gov/circs/sirc21.pdf.

Wagner, V. (2008). Processing reserves, seeking permissions and engaging the campus: How the library serves as the copyright touchstone. Journal of Interlibrary Loan, Document Delivery \& Electronic Reserve, 18(2), 247-254.

Woodman, B. (2007). Promoting course and electronic reserves to campus faculty. Journal of Interlibrary Loan, Document Delivery \& Electronic Reserve, 17(1/2), 183-211. 